Research Article

Xiaowei Yin, Wenxue Qian*, and Hoang Pham

\title{
Parametric simulation analysis and reliability of escalator truss
}

https://doi.org/10.1515/phys-2018-0115

Received Sep 08, 2018; accepted Oct 11, 2018

\begin{abstract}
Escalators are now more and more widely used around the world. As escalator accidents occur from time to time, it is very important to analyze the structure and reliability of escalators. This paper studies the structure and reliability analysis methods of typical escalators. By applying parametric analysis methods, the efficiency and accuracy of escalator structure analysis are greatly improved. Because the failure of each structural member of the escalator truss system is dependent, this paper applies the dependent failure reliability modeling method and analyzes the reliability of the escalator truss system. The results show that the reliability analysis method of the truss system after considering the dependent failure is more reasonable. The above research work has certain reference significance for the design and analysis of escalators.
\end{abstract}

Keywords: Escalator truss; dependent failure reliability; simulation analysis; finite element method

PACS: 62.20.mm, 05.20.-y

\section{Introduction}

With the growth of the global population, the acceleration of urbanization, and the improvement of people's requirements for convenient life, escalators are increasingly used.

\footnotetext{
*Corresponding Author: Wenxue Qian: School of Mechanical Engineering and Automation, Northeastern University, Shenyang 110819, China; Department of Industrial and Systems Engineering, Rutgers University, New Jersey 08904, United States of America; Key Laboratory of Vibration and Control of Aero-Propulsion Systems of Ministry of Education of China, Northeastern University, Shenyang 110819, China; Email: wxqian@mail.neu.edu.cn

Xiaowei Yin: School of Mechanical Engineering, Shenyang Institute of Engineering, Shenyang 110136, China; Department of Industrial and Systems Engineering, Rutgers University, New Jersey 08904, United States of America; Email: yxwqwx@163.com Hoang Pham: Department of Industrial and Systems Engineering, Rutgers University, New Jersey 08904, United States of America; Email: hoang84pham@gmail.com
}

In 1896, Jesse W. Reno built a machine much like an escalator at a playground. The playground was located on Coney Island in the United States because the machine provided a slope for use by tourists. In 1898 Charles Seeberger in cooperation with Otis, they produced a step with a level escalator and then in 1899 create the first commercial escalator. It won the first prize at the 1900 Paris World's Fair [1-3].

In recent years, the global installation and retention of escalators have continued to grow steadily. Accompanied by the ever-increasing economic level in many countries, the process of continuous urbanization, and the everincreasing quality of people's lives, the escalator industry has been continuously growing. With the development of society, people's requirements for modern escalators are getting higher and higher. Escalator truss is the support of the entire escalator system and is the key component of the entire escalator system. The reliability of the truss structure of the escalator directly determines safety of escalator and therefore becomes the focus of escalator research. Considering safety factors, if excessive parameters are selected in the calculation of the truss structure, excessive safety factors cause huge waste of steel materials, while not enough of them may lead to premature failure of the escalator. The cost reduction of escalators and improving product reliability have become the key to the continuous development of elevator companies [4-7].

\section{Escalator truss modeling and structure analysis}

As a means of transportation, escalators have the ability to transport large numbers of people upstairs or downstairs in a relatively short period of time. Due to their unique advantages, escalators are commonly used in department stores, shopping malls, luxury hotels, and stations where people flow is concentrated. The escalator is used between two floors of a building, and it is a continuous conveying machine that transports passengers reciprocating back and forth with crowds of reciprocating escalators.

The escalators have obvious advantages and are thus widely used. The escalator has large transport capacity, 


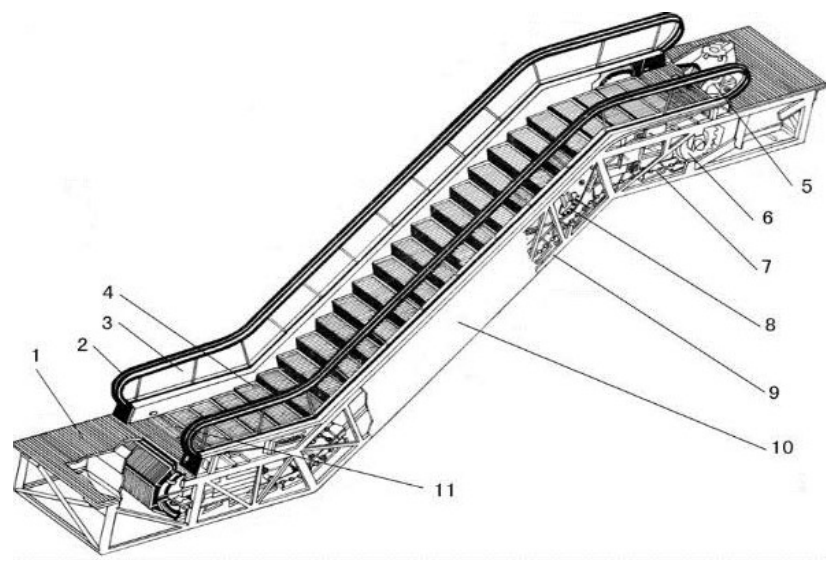

Figure 1: Escalator system

1- Lower cover; 2-Handrail; 3-Guardrail; 4-Race; 5-Power; 6-Step traction sprocket; 7-Traction rails; 8-Traction chain; 9-Truss; 10Outer trim board

can be reversed, can operate upwards and downwards, can continuously transport personnel, and deliver passengers with uniform flow; when power outages occur or parts need to be inspected to stop operation, they can be used as ordinary stairs. The escalators do not need to reserve additional supporting structures in the building, unlike the elevators, which need to reserve the hoistway; the overall shape of the escalator is very beautiful and very modern. It is both a means of transport and a special decoration of the building. The escalator model is shown in Figure 1.

\subsection{Structure modeling}

The escalator is a fixed-electric drive device with a cyclical rung for pitching passengers up or down, mainly by trusses, drives, braking systems, tensioners, rail systems, steps, chains, armrests and various safety devices.

The escalator metal truss is the basic member of the escalator, and is usually welded by ordinary type (angle steel, channel steel and flat steel) or square and rectangular tube. It has the function of installing and supporting various components, bearing various loads and connecting two different floors. The general escalator truss structure is shown in Figure 2, and the cross-section of the escalator truss structure is shown in Figure 3.

The escalator truss consists of an upper horizontal section, a lower horizontal section and a straight section. Common trusses are available in integral welded trusses (Figure 4) and split welded trusses (Figure 5). In order to facilitate manufacturing, lifting and packaging transportation, the factory generally makes the upper horizontal section and the lower horizontal section into standard sec- tions. The length of the straight section is determined by the lifting height. In the processing, a number of standard straight sections and non-standard straight sections are often made, according to the user. The required lifting heights are assembled and welded separately to form a closed structure truss.

The role of the metal truss determines that it must meet a certain stiffness, also to meet a certain degree of strength. The standard stipulates that for ordinary escalators or pedestrian crossings, the maximum deflection calculated or measured according to the passenger load shall not exceed the bearing distance; for public transport escalators or automatic pedestrian crossings, the maximum deflection calculated or measured according to the passenger load shall not be exceeding the support distance.

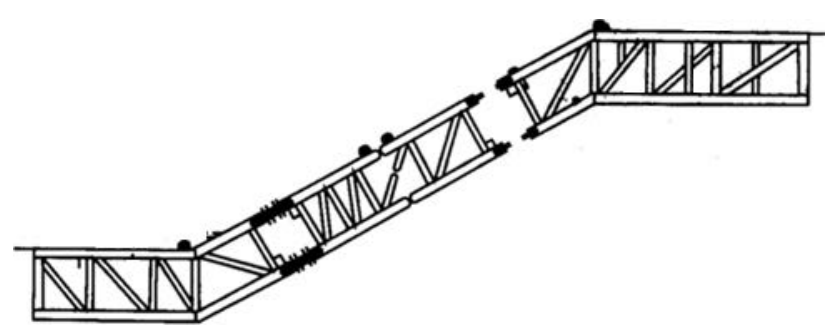

Figure 2: A model of truss system

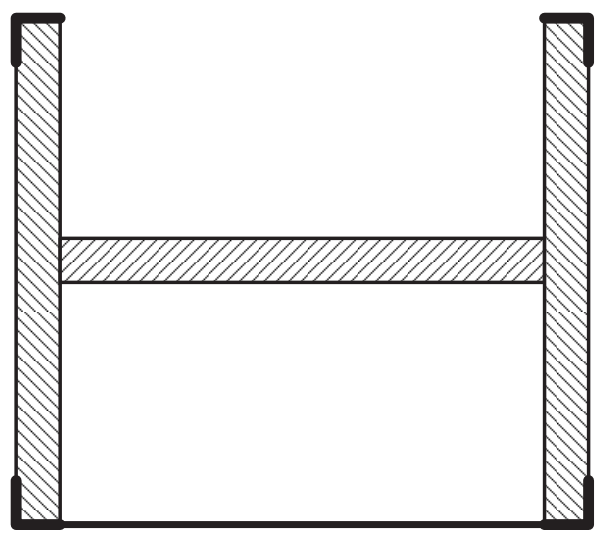

Figure 3: Schematic diagram of escalator truss section

In order to avoid the oscillating or vibration of the metal truss on the building, damping metal and damping rubber are filled between the fulcrum of the metal structure and the building.

The parameters of the escalator truss are shown in Table 1 . These dimensions can be automatically input into the finite element analysis software through the program. 


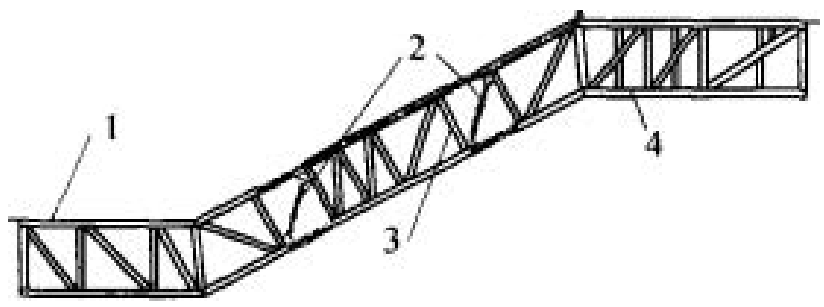

Figure 4: Front view of escalator truss

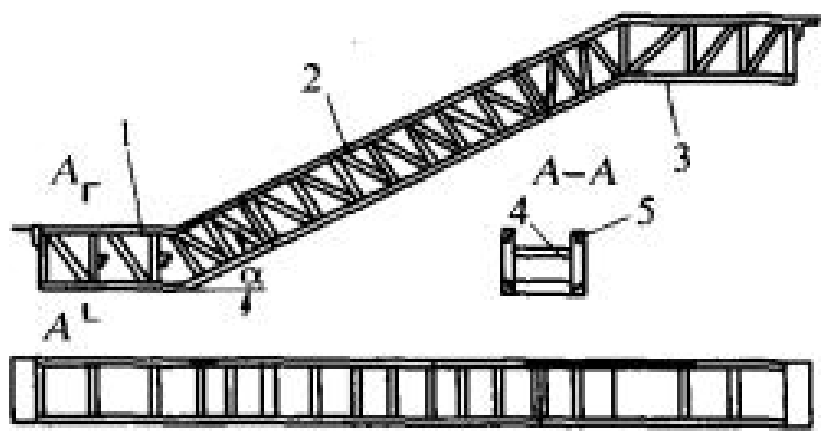

Figure 5: Top view escalator truss

For different escalators, modeling can be performed automatically.

An automatic modeling system was developed to automate the modeling and analysis of escalator trusses. Compared with the traditional system development, the system does not need to input complex parameters, and does not need to manually set the cross-section information of the member and generate complex operations such as the finite element model. It only needs to select the ladder type, height, inclination angle, etc. The basic truss parameters can automatically retrieve the relevant BOM in the database, generate modeling and analysis related files, automatically call ANSYS to realize the background calculation and analysis of the escalator truss, and present the calculation results on the system interface through fast calculation, fully realized automated analysis.

\subsection{Structure analysis}

Most cell types need to define material properties. The application of different material properties can be defined as linear or non-linear, isotropic, orthotropic anisotropy, or anisotropic, elastic or inelastic, not changing with temperature or as a function of temperature. Each set of material properties has a unique material reference number. A variety of materials can be used in one analysis, and correspondingly, material properties of multiple different material numbers need to be defined. The escalator truss structure uses a unit that is elastic, isotropic, and does not change with temperature. Its metal structure material is Q235 steel. The material parameters are shown in Table 2.

Meshing is a very important part of the analysis process. The quality of the mesh directly determines the calculation time and calculation accuracy required for the analysis. The unqualified mesh will not only increase the calculation time, but also affect the calculation accuracy. Even because of poor meshing, it cannot be calculated. Meshing is divided into free meshing and mapping meshing. The free mesh is suitable for irregular shapes, but the calculation accuracy is not as good as the mapping mesh. The mesh after the mapping has a certain shape rule. Therefore, the best practice is to use free meshing in complex border areas, and use non-border areas to use mapping partitions. The meshed model is shown in Figure 6.

After the finite element model is generated, it cannot be calculated yet, and boundary conditions need to be applied, including applying loads and constraints. A constraint is imposed to limit the degree of freedom of the boundary node. The number of degrees of freedom applied depends on the number of degrees of freedom in which boundary nodes are limited in the display case. In this paper, the escalator truss, according to the actual situation of the force, should deal with the upper and lower ends of the full angle steel, including the X, Y, Z direction translation and rotation. If there is intermediate support, the $\mathrm{Y}$ direction constraint needs to be imposed on the intermediate support.

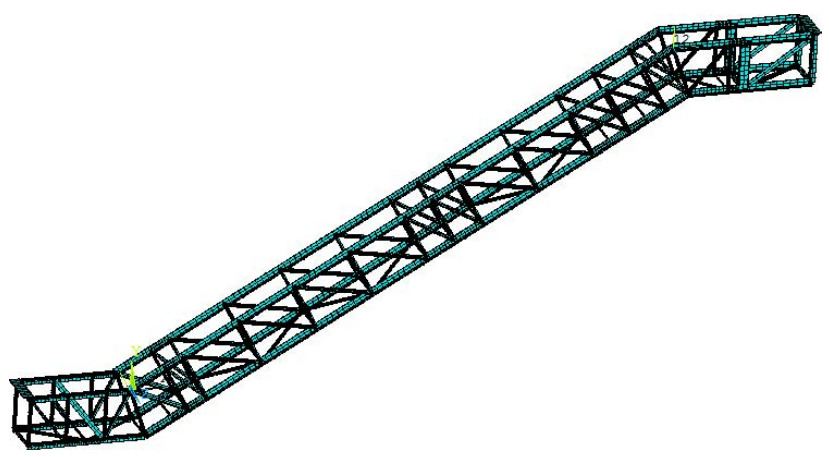

Figure 6: Escalator steel-framed structure meshing model

There are two kind of loads, self loading and passenger load. The weight of the entire escalator system includes the weight of several components such as metal frame structures, steps, traction chains, stair rail systems, drive devices, tensioning devices, and handrail devices. According to the actual load situation, the key concentrated point of the two upper chords is applied in the form of equivalent 
Table 1: Modeling parameters

\begin{tabular}{cccccccccc}
\hline $\begin{array}{c}\text { Lifting } \\
\text { height }(\mathrm{m})\end{array}$ & Dip $(\mathrm{m})$ & $\begin{array}{c}\text { Width } \\
(\mathrm{m})\end{array}$ & $\begin{array}{c}\text { Lower } \\
\text { exten- } \\
\text { sion } \\
(\mathrm{m})\end{array}$ & $\begin{array}{c}\text { Upper } \\
\text { exten- } \\
\text { sion } \\
(\mathrm{m})\end{array}$ & $\begin{array}{c}\text { Lower } \\
\text { truss } \\
\text { length } \\
(\mathrm{m})\end{array}$ & $\begin{array}{c}\text { Number } \\
\text { of lower } \\
\text { truss }\end{array}$ & $\begin{array}{c}\text { Upper } \\
\text { truss } \\
\text { length(m) }\end{array}$ & $\begin{array}{c}\text { Number } \\
\text { of upper } \\
\text { truss }\end{array}$ & $\begin{array}{c}\text { Variable } \\
\text { segment } \\
\text { size(m) }\end{array}$ \\
\hline 6 & 30 & 0.8 & 0 & 0 & 6.527 & 4 & 5.423 & 2 & 0.89 \\
\hline
\end{tabular}

Table 2: Material parameters

\begin{tabular}{ccccc}
\hline Material & $\begin{array}{c}\text { Elastic } \\
\text { Modulus } \\
(\mathrm{GPa})\end{array}$ & $\begin{array}{c}\text { Poisson's } \\
\text { ratio }\end{array}$ & $\begin{array}{c}\text { Yield } \\
\text { strength } \\
(\mathrm{MPa})\end{array}$ & $\begin{array}{c}\text { Density } \\
\left(\mathrm{Kg} / \mathrm{m}^{3}\right)\end{array}$ \\
\hline Q235 & 210 & 0.3 & 235 & 7800 \\
\hline
\end{tabular}

concentrated force. Passenger load is $5000 \mathrm{~N} / \mathrm{m} 2$. According to the length and width of the escalator, the load carried by the ladder can be calculated, which is equivalent to the concentrated load acting on the nodes of the two upper chords. The loads were applied as shown in Figure 7. Figure 8 shows the FEA result, where the max stress is $65.7 \mathrm{MPa}$, which is lower than the yield stress of truss material.

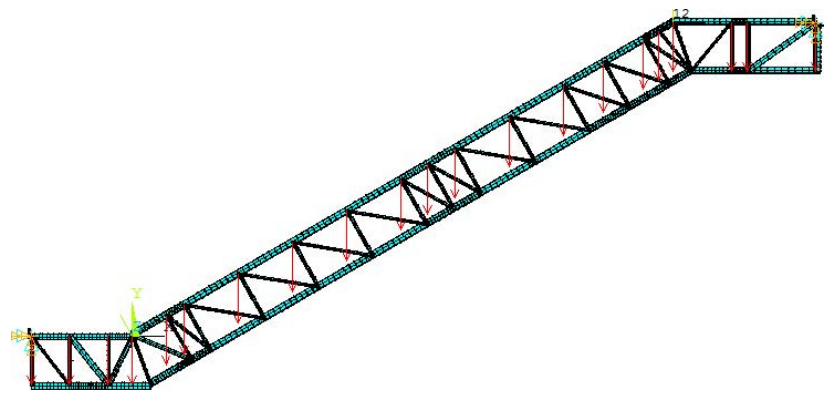

Figure 7: Schematic diagram of loads application

\section{Reliability analysis}

The escalator truss structure is a complex system that normally bears the effect of self-weight loads and passenger loads. The deadweight is the static load, the passenger load is the random load, the passenger load during the peak period is large, and the passenger load during the low peak period is very small. Because the truss structure bears the effect of random loads, there is a failure dependent between the truss rods and the beams. For the truss system, no structural failure is allowed. Therefore, from a

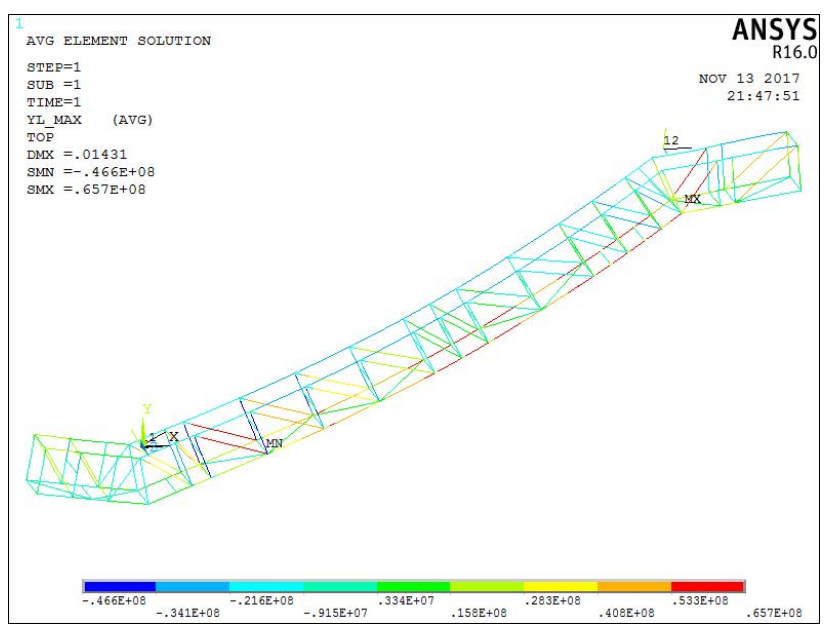

Figure 8: Escalator steel-framed structure stress nephogram

reliability standpoint, the escalator truss structure is a series system [8-10].

Assuming that the probability density function of truss strength is $g(s)$ and the distribution function is $G(s)$, the probability density function of stress is $f(\delta)$ and the distribution function is $F(\delta)$. The escalator truss structure has $k$ dangerous components, and the observed strength values of the components sites are $s_{1}, s_{2}, \ldots, s_{n}$. The rank of these values from smallest to biggest is as follows:

$$
s_{(1)}<s_{(2)}<s_{(3)} \ldots s_{(n)}
$$

From probability and statistics theory, it can be seen that $s_{(1)}, s_{(2)}, s_{(3)}, \ldots, s_{(n)}$ are the order statistics.

$$
\begin{gathered}
g_{(1)}(s)=n g(s)\left[\int_{s}^{\infty} g(s) d s\right]^{n-1} \\
G_{(1)}(s)=1-[1-G(s)]^{n}
\end{gathered}
$$

According to the minimal order statistics theory and dependent failure theory the following formula can be obtained:

$$
R=\int_{0}^{\infty} f(\delta) \int_{\delta}^{\infty} g_{(1)}(s) d s d \delta=\int_{0}^{\infty} f(\delta)[1-G(\delta)]^{n} d \delta
$$


This formula reflects the dependent failure of the component. Based on the Equation (3), substituting the distribution values of $g(s) \sim(235,11.752) \mathrm{MPa}$ and $\mathrm{f}(\delta) \sim(65.7$, 6.572)MPa, the reliability can be calculated to $99.9999 \%$.

\section{Conclusions}

The truss structure is the key support system for escalators, ensuring its reliability and safety, which are extremely important. Based on the finite element method, this paper analyzes the stress distribution of a typical escalator truss structure subjected to random loads, determines the dangerous locations and stress levels of the truss structure, and establishes the theory of dependent failure due to the effect of random loads applying on the truss system. The reliability model of the truss system is analyzed and the reliability of the truss system is analyzed and calculated. The safety and reliability of the truss system and the effectiveness of the method presented in this paper are verified.

Acknowledgement: This work was partially supported by the National Natural Science Foundation of China (Grant No. 51305275, 51335003, U1708255), the Program for Liaoning Excellent Talents in University (Grant No. LR2015044) and the China Scholarship Council (Grant No. 201708210039, 201706085029).

\section{References}

[1] Liang J., Study of FEA Static Analysis Application on the Calculation of Escalator Truss, Mech. Electr. Eng. Technol., 2014, 6, 102-109.

[2] Uimonen S., Tukia T., Siikonen M.L.,et al., Energy consumption of escalators in low traffic environment, Energy Build., 2016, 125, 287-297.

[3] Bardyshev O., Popov V., Druzhinin P. et al., Expert Review of Metro Escalators Safety, Transport. Res. Procedia, 2017, 20, 3135.

[4] Xie L., Liu J., Wu N., Qian W., Backwards statistical inference method for P-S-N curve fitting with small-sample experiment data, Int. J. Fatigue, 2014, 63, 62-67.

[5] Wang Z., Xie L., Dynamic reliability model of components under random load, IEEE Trans. Reliab., 2008, 57(3), 474-479.

[6] Gao P., Yan S., Xie L., Dynamic reliability analysis of mechanical components based on equivalent strength degradation paths, Strojniski Vestnik-J. Mech. Eng., 2013, 59(6), 387-399.

[7] Yin X., Common Cause Failure Model of System Reliability Based on Bayesian Networks, Int. J. Perform. Eng., 2010, 6(3), 160-170.

[8] Qian W., Yin X., Xie L., Reliability modeling and assessment of component with multiple weak sites under complex loading, Math. Probl. Eng., 2014, 2014, 1-9.

[9] Qian W., Yin X., Xie L., System reliability allocation based on bayesian network, Appl. Math. Inform. Sci., 2012, 6, 681-687.

[10] Freudenthal A.M., Carrelts M., Shinozuka M., The analysis of structural safety, J. Struct. Div., ASCE, 1966, 92, 267-325. 